Iooft., and that with a cloudy sky it is only half what it is with a clear sky. These results were from the mean of his observations; under exceptional circumstances the variations were both greater and less. It is hence shown that rays of sound otherwise horizontal would be bent upwards in the form of circles, the radii of which with a clear sky are Iro,00o ft., and with a cloudy sky $220,000 \mathrm{ft}$., so that the refraction is double as great on bright hot days as it is when the sky is cloudy, and still more under exceptional circumstances, and comparing day with night.

It is then shown by calculation that the greatest refraction-r ro, $000 \mathrm{ft}$. radius-is sufficient to render sound from a cliff $235 \mathrm{ft}$. high inaudible on a ship's deck $20 \mathrm{ft}$. high at $\mathbf{I}_{4}^{\frac{3}{4}}$ miles, except such sound as might reach the observer by divergence from the waves above, whereas when the refraction is least-220,000 ft. radius-or where the sky is cloudy, the range would be extended at $2 \frac{1}{2}$ miles with a similar extension for the diverging waves. It is hence inferred that the phenomenon which Prof. Tyndall observed on July 3 , and other days--namely that when the air was still and the sum was hot he could not hear guns and sounds from the cliffs of South Foreland, $235 \mathrm{ft}$. high, for more than two miles, whereas when the sky clouded, the range immediately extended to three miles, and as evering approached much farther, - - was due, not so much to stoppage or to reflection of the sound by invisible vapour as Prof. Tyndall has supposed, but to the sounds being lifted over his head in the manner described; and that had he been able to ascend $30 \mathrm{ft}$. up the mast, he might at any time have extended the range of the sound by a quarter of a mile at least. Or had the instruments on the top of the cliff been compared with similar instruments at the bottom, a very marked difference would have been found in the distances at which they could be heard.

It seems that there were instruments at the bottom, and it is singular that throughout his report Prof. Tyndall makes no comment on their performance, unless they were at once found to be so inferior to those at the top that no further notice was taken of them; this seems possible, since beyond mentioning that they were there, Prof. Tyndall throughout his report never refers to them.

It also seems that besides those results of Prof. Tyndall's experiments, there are many other phenomena connected with sound, of which this refraction affords an explanation, such as the very great distances to which the sound of meteors has been heard as well as the distinctness of distant thunder. When near, guns make a louder and more distinctive sound than thunder, although thunder is usually heard to much greater distances. In hilly countries, or under exceptional circumstances, sounds are sometimes heard at surprising distances. When the Naval Review was at Portsmouth, the volleys of artillery were very generally heard in Suffolk, a distance of 150 miles. The explanation being that owing to refraction (as well as to the other causes) it is only under exceptional circumstances that distant sounds originating low down are heard near the ground with anything like their full distinctness, and that any elevation either of the observer or of the source of sound above the intervening ground causes a corresponding increase in the distance at which the sound can be heard.

\section{SCIENTIFIC SERIALS}

Menorie della Societa degli Spectroscopisti Italiani, February.Father Secchi contributes a paper On his Observations of Solar Prominences from April 23 to October 2, 1873 . From his tables it appears that the sun was observed on 127 days, when I,052 prominences were seen, being more than 8 a day, the maximum number visible on any one day was 13 , and the minimum 2. The greatest number of prominences over $64^{\prime \prime}$ high occurred in lat. $30^{\circ} 40^{\prime} \mathrm{N}$. and $20^{\circ} 30^{\prime} \mathrm{S}$. The greatest number of prominences of all kinds were in lat. $20^{\circ} 30^{\prime} \mathrm{N}$. and $10^{\circ} 20^{\prime} \mathrm{S}$. The same author also makes some remarks on the spectroscopic observations of the transit of Venus.

Astronomische Nachrichten, Nos. 1,980-1,98. I. - These numbers contain a large quantity of observations of positions of the minor planets and comets made in 1873 by Leopold Schulhof. $\mathrm{He}$ also gives the positions of more than roo variable stars, with remarks on a new variable position for 1850 , RA $23^{\circ} \mathrm{IO}^{\prime} 35^{\prime \prime}$ Dec. $-19^{\circ} 39^{\prime} \%$. Prof. Peters gives the position of Planet 135, Feb. I8, 1874, at $14 \mathrm{~h} .37 \mathrm{~m}$. 40s., Hamilton College, M.T., RA I rh. I9m. $42^{\circ} 7 \mathrm{~s}$. Dec, $+4^{\circ} 25^{\prime} 5^{\prime \prime} \cdot$ II mag. G. Spoerer gives the positions of spots and prominences for February last. $\mathrm{J}$. Palisa gives the position of the planet discovered by him on March I8, 4h. 46m. 39s. RA I2h. 22m. 2'I2s. Dec. $-3^{\circ} 19^{\prime} 33^{\prime \prime} 4$.

No. I, 982 contains a long paper On a Method of Computing A.bsolute Perturbation, being in great measure similar to that of Laplace.

Fournal of the Franklin Institute, March.-This number contains an account, by $\mathrm{Mr}$. Crew of the "prismoidal" onerail railway (of his invention), of which he has made two years' trial in Alabama, with encouraging resuits. The cars are kept securely on the prismoidal track by a combination of wheels; a centre one, at either end, on the rail, kept on the track by revolving flanged wheels at either side; and wheels on the sides of the prismoid, with strong wrought-iron bars to the side of the car ; these keep the car upright. One proposed application of the system is that of elevated rapid transit by steam through crowded streets in populous cities. As to speed, Mr. Crew thinks even 100 miles an hour would be possible; there is no oscillation through lateral motion.-Mr. Richards continues his Principles of Shop Manipulation for Engineering Apprentices; treating of belts, gearing, hydraulic and pneumatic apparatus as means of transmitting power, and of "machinery of application " of power--Mr. Isherwood points out a method of ascertaining what portion of the feed-water admitted to a boiler is entrained in the form of spray by the escaping steam. - Details with reference to the Girard Aventie Bridge (which will form the chief entrance to the West Park, at Philadelphia), are furnished by Mr. Hering.-Prof. Thurston claims for Count Rumford a higher place in connection with thermo-dynamics than has hitherto been assigned to him; affirming that he first, and half a century before Joule, determined with almost perfect accuracy the mechanical equivalent of heat, while the sole credit of discovering the true nature of heat is due to him.-- We may note, in addition, a paper On Railway Crossings and Turnouts, by $\mathrm{Mr}$. Evans, and one On the Sanitary Care and Utilisation of Refuse in Cities, by Dr. Leas, who describes, more especially, the system followed in Baltimore.

\section{SOCIETIES AND ACADEMIES} LONDON

Royal Society, April 23.- On some points connected with the Circulation of the Blood, arrived at from a study of the Sphygmograph Trace, by A. H. Garrod, B.A., Fellow of St. John's College, Cambridge.

The author commences by giving a table containing a fresh series of measurements of the ratio borne by the cardiosystole * to its component beat in the cardiograph trace. These tend strongly to substantiate the law previously published by him, viz., that the length of the cardiosystole is constant for any given pulse-rate, and that varies as the square root of the length of the pulse-beat only, being found from the equation $x y=20 \mathrm{~V} x$ when $x=$ the pulse-rate and $y=$ the ratio borne by the cardiosystole to the whole beat.

A similar series of fresh measurements are given in proof of the law previously published by him, that in the sphygmograph trace from the radial artery at the wrist, the length of the sphygmosystole $\dagger$ is constant for any given pulse-rate, but varies as the cube-root of the length of the pulse-beat, it being found from the equation $x y^{\prime}=47 \sqrt[3]{x}$, where $x=$ the pulse-rate, and $y^{\prime}=$ the ratio borne by the sphygmosystole to the whole beat.

By measurement of sphygmograph tracings from the carotid in the neck and posterior tibial artery at the ankle, it is then shown that the length of the sphygmograph in those arteries is exactly the same as in the radial; so that the above-stated law as to the length of the sphygmosystole in the latter applies to them also, and must therefore equally apply to the pulse in the aorta.

Such being the case, by comparing the equations for finding the length of the cardiosystole with that for finding the aortic sphygmosystole, the relation between the whole cardiac systolic act and the time during which the aortic valve remains open can be estimated with tacility; for by subtracting the shorter sphygmosystole from the longer cardiosystole a remainder is obtained which can be nothing else than the expression of the

* The cardiosystole is the interval betwcen the commencement of the systole and the closure of the aortic valve in each revolution.

+ The sphygmosystole is the interval between the opening and closure of the aortic valve in each cardiac revolution. 